\title{
Crise, desenvolvimento e políticas de industrialização no Brasil de Getúlio Vargas
}

\section{Crisis, development and industrialization policies in Getulio Vargas' Brazil}

\section{Resumo}

As relações entre Brasil e Estados Unidos foram fundamentais ao desenvolvimento da indústria de base nacional, a uma retomada do preço internacional do café, ao reaparelhamento das forças armadas e para renegociação de dívidas, bem como para a concessão de empréstimos ao país. Neste artigo, analisamos o primeiro governo de Getúlio Vargas e como ele se beneficiou do comércio bilateral.

Palavras-chave: Economia. Desenvolvimentismo. Getúlio Vargas.

\begin{abstract}
Relations between Brazil and the United States were fundamental to the development of national industry, the resumption of international coffee prices, the modernization of the armed forces and for renegotiating debts, as well as the country's international loans. In this article, we analyze the first government of Getúlio Vargas and how he benefited from bilateral trade.
\end{abstract}

Keywords: Economy. Developmentalism. Getúlio Vargas.

Doutoranda e Mestre em Ciências Sociais com especialidade em Análise Comparativa das Américas pelo Centro de Pesquisa e Pós-Graduação Sobre as Américas (CEPPAC) da Universidade de Brasília (UnB). Bacharel em Direito pelo UniCEUB. Bolsista da CAPES em 2010-2011. Bolsista do CNPq em 2006-2008 e 2013-2014. Vice-Líder do Grupo de Estudos do MERCOSUL, vinculado ao UniCEUB. Autora do livro "Mercosul: sobre democracia e instituições" e coordenadora do livro "Direito do Mercosul". 


\section{Introdução}

Um período que certamente redefiniu as bases da economia brasileira foi aquele compreendido entre os anos 1930 e 1960. A industrialização e a modernização econômicas eram dois dos pilares das políticas do período, cujos efeitos podem ser percebidos no atual cenário nacional. A corrente de pensamento desenvolvimentista serviu como base ideológica para os governantes cujos programas visavam à substituição de importações, ao fortalecimento da indústria nacional e a uma maior autonomia do mercado interno brasileiro. Pode-se dizer que Getúlio Vargas foi o primeiro presidente a defender esse tipo de política de forma ostensiva e sistemática, tendo marcado a época com suas políticas de fortalecimento do Estado e de fomento à autonomia nacional. Nos primeiros anos do seu governo, a economia mundial vivenciava um período de contração que se havia iniciado no início dos anos 1930 devido à crise da bolsa de Nova Iorque e aos resquícios, no campo econômico e político, que a Primeira Guerra Mundial deixava no mercado europeu e norte-americano.

O financiamento do nacional-desenvolvimentismo varguista era um tanto quanto heterodoxo, em contraposição com as suas políticas internas, pois se beneficiava de relações estabelecidas com base em uma luta de influências no âmbito ideológico e das relações internacionais. Estados Unidos e Alemanha foram escolhidos como parceiros não por mero acaso, mas pela relação que detinham com a política desenhada por Vargas: as relações comerciais e diplomáticas com os Estados Unidos permitiram ao Brasil contrair empréstimos, renegociar dívidas e adquirir diversos insumos para fomentar a incipiente indústria que se pretendia estabelecer. Por seu turno, as relações com a Alemanha, viabilizavam trocas comerciais, apoio político e maior poder de barganha com a potência norte-americana.

A análise da referida temática se focará na primeira gestão de Getúlio Vargas (1930-1945), haja vista que há diferenças marcantes entre os dois governos. No entanto, serão realizadas menções aos dois períodos. Pode-se dizer que de 1930 a 1945, o governo de Getúlio Vargas foi marcado por políticas conservadoras do ponto de vista econômico e por uma política externa heterodoxa marcada pela "equidistância pragmática" entre Estados Unidos e Alemanha. Essa opção deu-se especialmente em consequência das crises econômica e política vividas no pós-crise de 1929, que afetaram fortemente as exportações brasileiras, impactando na balança de pagamentos do país e, em consequência, do endividamento do Estado. A opção por uma barganha entre as duas nações foi o que possibilitou a Vargas investir no seu modelo de desenvolvimento.

Na primeira parte deste trabalho, serão abordadas as principais consequências da crise de 1929 na economia brasileira dos anos 1930, tais como o desequilíbrio das contas públicas, a queda do preço do café, a diminuição das exportações, a desvalorização da moeda nacional e o crescimento do endividamento externo. Em seguida, abordaremos as relações do Brasil com os Estados Unidos e com a Alemanha, na busca pelo desenvolvimento da indústria e da economia nacionais. Em seguida, trataremos brevemente sobre o segundo governo de Vargas (1951-1954), da mudança nos rumos da condução dos negócios nacionais a partir de políticas protecionistas; será promovido um balanço do desenvolvimento pátrio, especialmente no que tange ao setor cafeeiro e industrial. Por fim, serão apresentadas conclusões a respeito do projeto de desenvolvimento nacional da época.

\section{Desenvolvimentismo: o grande pilar ideo- lógico de Getúlio Vargas}

Segundo Leys (1996), a teoria do desenvolvimento surgiu nos anos 1950 com o claro objetivo de transformar as economias das ex-colônias europeias e inseri-las em um novo paradigma de competitividade. Por seu turno, Fonseca (2010) aponta que o nacional desenvolvimentismo é um fenômeno latino-americano e não uma simples importação de ideias preconcebidas e aceitas sem modificações. O autor entende que a origem do desenvolvimentismo nacional foi o Rio Grande do Sul, por volta dos anos 1920. Para ele, o discurso desenvolvimentista, que seria o pilar ideológico da Comissão Econômica para a América Latina e o Caribe nos anos 1950, já estava presente muito antes da concepção de um conjunto fundamentado de princípios e ideias, podendo ser percebido nas palavras proferidas por Getúlio Vargas, quando de sua posse como Presidente do Rio Grande do Sul, em 1928 (FONSECA, 2004, p. 17). No Brasil, o desenvolvimentismo se estendeu até a década e 1980, resultado, principalmente, do amálgama de quatro correntes de pensamento: o nacionalismo; o positivismo; o industrialismo; e o papelismo.

$\mathrm{O}$ desenvolvimentismo brasileiro é definido por 
Fonseca (2004, p. 2) como um "conjunto comum de ideias concatenado e estruturado" em torno de um núcleo duro: a industrialização; o intervencionismo pró-crescimento; e o nacionalismo. O argumento de que "sem uma política consciente e deliberada não se pode falar em desenvolvimentismo" (FONSECA, 2004, p. 2) reflete sua tese de que o desenvolvimentismo no Brasil se apoia nos três pilares referidos e teve sua origem nas quatro correntes de pensamento citadas anteriormente.

O professor contradiz certas ideias arraigadas de que o desenvolvimentismo no Brasil surgiu apenas após a Revolução de 1930. Também contraria o senso comum de que a política industrializante da Era Vargas foi iniciada como simples efeito não previsto ou não querido da proteção do setor cafeeiro diante da crise de 1929. Ele afirma que o desenvolvimentismo começou já em 1928 (FONSECA, 2004, p. 17) e que as políticas industrializantes da década de 1930 foram intencionais. (FONSECA, 2003), baseado em sólida pesquisa de fontes, inclusive primárias, apresentando alternativas plausíveis para teorias antigas.

Para alcançar os objetivos de seu plano, Vargas teria ressaltado a necessidade de um crescimento acelerado da economia, que seria alcançado por meio de um misto de investimentos público e privado, sendo este voltado para a produção de bens de consumo e aquele para a infraestrutura (FONSECA, 2010). Com o passar dos anos de governo de Getúlio, o desenvolvimentismo brasileiro ia cada vez mais se firmando como ideologia voltada ao "reordenamento de leis e práticas de política econômica, bem como mudanças e criação de instituições" (FONSECA, 2003, p. 142). As principais características do desenvolvimentismo brasileiro da época eram o protecionismo à indústria nacional, a forte intervenção estatal no comércio exterior, a captação de empréstimos internacionais para o financiamento dos projetos de industrialização e o investimento em indústrias de base.

Segundo Bielschowsky (apud VIGEVANI; RAMANZINI, 2009, p. 19), Celso Furtado propunha três eixos na condução do desenvolvimentismo:

\begin{abstract}
A liderança do Estado na promoção do desenvolvimento, por meio de investimentos em setores estratégicos e, sobretudo, do planejamento econômico, coordenando esforços de industrialização, de forma a reunir condições para superar os obstáculos estruturais que dificultavam o desenvolvimento.
\end{abstract}

A defesa da tese estruturalista da submissão da política monetária e cambial à política de desenvolvimento, base da argumentação nacionalista, em oposição aos programas de estabilização, sendo o sucesso da industrialização brasileira dependente fortemente do controle que os agentes nacionais pudessem ter sobre as decisões fundamentais à economia do país.

Um compromisso com reformas de cunho social, inclusive, com a reforma agrária, pois havia forte percepção sobre a importância do mercado interno na dinamização da produção e da renda.

Para Furtado, as possibilidades dinâmicas de superação da dependência do comércio exterior, ou de superação do próprio subdesenvolvimento, pela via de crescimento, só trariam resultados concretos mediante o fortalecimento do mercado interno (BIELSCHOWSKY, apud VIGEVANI; RAMANZINI, 2009, p. 19). O processo de industrialização, associado à urbanização, trouxe um conjunto de medidas que podem ser identificadas como as bases do intervencionismo de Vargas. Por entender que a sociedade brasileira necessitava desenvolver-se, e que esse desenvolvimento só seria possível com a intervenção estatal, o Governo Vargas, ao longo do período 1930-1945, editou leis, normas e, mesmo, constituições, que institucionalizaram a intervenção econômica no ordenamento jurídico brasileiro.

Inspirada na Constituição de Weimar (19191934), a Constituição brasileira de 1934 adotou algumas medidas liberais, como a ampliação do direito de sufrágio para as mulheres, a instituição do voto classista e a concessão de maior autonomia aos estados. Entretanto, no domínio econômico, medidas bastante intervencionistas foram adotadas. No artigo 116, era prevista a possibilidade de o Estado monopolizar certas atividades econômicas:

Art 116 - Por motivo de interesse público e autorizada em lei especial, a União poderá monopolizar determinada indústria ou atividade econômica, asseguradas as indenizações, devidas, conforme o art. 112, $\mathrm{n}^{\circ} 17$, e ressalvados os serviços municipalizados ou de competência dos Poderes locais. (BRASIL, 1934)

De igual sorte, no artigo 119 , parágrafo $4^{\circ}$, previa-se a progressiva nacionalização de outras atividades:

Art 119. $\$ 4^{\circ}$ - A lei regulará a nacionalização progressiva das minas, jazidas minerais e quedas d'água ou outras fontes de energia hidráulica, julgadas básicas ou essenciais à defesa econômica ou militar do País. (BRASIL, 1934)

No entanto, a Constituição previa também a pro- 
teção do Estado à economia popular, por meio do controle do setor financeiro. Pretendia ordenar as atividades econômicas para o progresso dos setores mais fracos:

Art 117 - A lei promoverá o fomento da economia popular, o desenvolvimento do crédito e a nacionalização progressiva dos bancos de depósito. Igualmente providenciará sobre a nacionalização das empresas de seguros em todas as suas modalidades, devendo constituir-se em sociedades brasileiras as estrangeiras que atualmente operam no País. (BRASIL, 1934)

A Constituição de 1934 foi inspirada por princípios democráticos e liberais. Embora previsse a possibilidade de nacionalização de empresas, garantia a liberdade econômica como fundamento necessário para alcançar a existência digna para todos (art. 115). Mas por ter sido redigida logo após uma crise econômica mundial, e para se adequar a uma organização burocrática mais moderna e adepta do liberalismo econômico, previa a impossibilidade de garantia de juros a empresas concessionárias de serviços públicos (art. 142).

Por seu turno, a Constituição de 1937 foi inspirada na Constituição polonesa de 1935, autoritária e com traços bastante intervencionistas na economia. Foi outorgada em 10 de novembro, mesmo dia em que se instalou a ditadura do Estado Novo. Como a Constituição anterior, de 1934, previa inúmeras normas sobre a intervenção do Estado nos mais diferentes setores econômicos.

Entre suas normas, vale destacar a centralização das decisões sobre projetos de lei versando sobre a economia no Conselho da Economia Nacional (art. 65); a previsão, como na Constituição de 1934, da nacionalização de minas e potenciais hidráulicos (art. 144); a obrigatoriedade de possuir porcentagem de empregados brasileiros (art. 153); o controle sobre as faixas fronteiriças.

Resultado das mudanças democráticas causadas, entre outras razões, pela vitória dos Aliados na Segunda Guerra Mundial, a Constituição brasileira de 1946 pode ser considerada a mais liberal das três, sem as características corporativas da de 1934, nem os traços autoritários da de 1937. Aberta às mais diferentes correntes ideológicas, não deixou de prever a possibilidade de intervenção econômica do Estado na economia. Aliás, foi a primeira Constituição brasileira a citar expressamente a intervenção no domínio econômico:

Art 146 - A União poderá, mediante lei especial, intervir no domínio econômico e monopolizar determinada indústria ou atividade. A intervenção terá por base o interesse público e por limite os direitos fundamentais assegurados nesta Constituição. (BRASIL, 1934)

Diferentemente, no entanto, das outras duas constituições, já não previa a possibilidade de nacionalização progressiva das minas, tampouco a obrigatoriedade de porcentagem de trabalhadores brasileiros nas empresas. Previa expressamente o combate aos cartéis, trustes ou outras formas de burlar a concorrência (art. 148). Mais uma vez controlava o acesso à propriedade nas faixas de fronteira (art. 180).

\section{Efeitos da crise de 1929 na economia brasi- leira e o projeto nacional-desenvolvimen- tista}

O setor cafeeiro, bastante afetado com vários choques, recebeu especial atenção de Vargas, principalmente durante seu primeiro governo. Na década de 1930, houve um declínio dramático nas exportações brasileiras de café, que antes da crise giravam em torno do montante de 446 milhões de dólares e em 1932 caíram para a quantia de 180 milhões de dólares (BAER, 2009, p. 54). Devido à queda do preço do café, as relações de troca do país decaíram pela metade. Como consequência, houve também escassez de produtos manufaturados por causa da redução da receita de exportação, uma vez que, de acordo com Baer (2009, p. 54-55), o ingresso de capital estrangeiro no país era quase nulo. O café correspondia a $71 \%$ das exportações nacionais (o equivalente a 10\% do Produto Nacional Bruto) e a queda no valor de suas exportações era motivo de consternação.

Segundo dados do Instituto Brasileiro de Geografia e Estatística- IBGE, houve significativo decréscimo no valor unitário de exportação do café nos primeiros anos da década de 1930. Essa tendência somente se reverteu dez anos depois, e alcançou os patamares mais altos somente ao final do segundo governo de Getúlio, em 1954. A volatilidade dos preços de exportação do café manteve-se na faixa de 30\% a 40\% entre os anos 1928 e 1937, também alcançando seu pico após a eleição de Vargas, em 1951. Em face da grave situação, foi promovida a criação de órgãos especializados na formulação e no acompanhamento das políticas cafeeiras. O Conselho Nacional do Café e o Departamento Nacional do Café foram criados com o intuito promover uma mudança nos patamares da época. O CNC era um colegiado formado por membros advindos dos estados produtores do grão, como Minas 
Gerais e São Paulo, e o DNC composto por diretores indicados pelo ministro da Fazenda (FAUSTO, 2006, p. 45).

Dentre as medidas internacionais adotadas para a reinserção do café na pauta exportadora, está a forte participação do Brasil na Conferência Internacional do Café, em 16 de junho de 1931, que tinha por objetivo restringir a produção mundial e, por conseguinte, aumentar seu preço no mercado internacional. No âmbito da Conferência, foi adotado o compromisso de criação de um Bureau Internacional do Café (GARCIA, 2005, p. 143), que funcionaria como agência de controle e fomento.

De acordo com Celso Furtado (2007, p. 253) e Baer (2010), o governo brasileiro, com o intuito de retomar o reequilíbrio entre oferta e procura de café, começou a comprar massivamente o excedente, para diminuir sua oferta na economia mundial e, consequentemente, aumentar o preço, o que protegeria o setor cafeeiro da crise mundial. O financiamento da compra dos excedentes, até o ano de 1929, era feito com capital estrangeiro, cujos serviços eram pagos com a renda de imposto cobrado sobre a saca de café (FURTADO, 2007, p. 253-254).

Nos anos 1930, o governo comprava grande parte da produção a um baixo valor e a revendia no exterior, acumulando reservas internacionais ${ }^{2}$. Com vistas a solucionar o problema no longo prazo, mais uma vez foi promovido o desencorajamento da expansão da produção para não haver nova queda no preço internacional dessa commoditie (FURTADO, 2007, p. 254). Tal política econômica obteve resultados positivos, uma vez que estimulou o crescimento da renda nacional, possibilitando um aumento do poder aquisitivo e consequente dinamização da economia (BAER, 2009, p. 57-58). A queima do café teve seu fim em julho de 1944, quando já haviam sido destruídas 78,2 milhões de sacas, quantidade aproximadamente análoga a três anos do consumo mundial da commoditie (FAUSTO, 2006, p. 44).

Marinho e Lourenço (2009, p. 182) relembram o importante caráter da industrialização no modelo de desenvolvimento brasileiro. Os autores afiram que:

A industrialização e a efetiva reorganização dos mercados após a crise econômica de 1929 e a Segunda Guerra Mundial reuniram um conjunto de expectativas e um arcabouço teórico que se

2 “[...] a destruição dos excedentes se impunha, portanto, como uma consequência lógica da política de continuar colhendo mais café do que se podia vender." (FURTADO, 2007, p. 267) aplicou como substituto ideal para o monótono destino dos países latino-americanos exportadores de matérias primas. Logo, o fenômeno da industrialização foi um marco para os estudos sobre o desenvolvimento e o pensamento dominante da teoria da modernização de Rostow, um modelo evolutivo que determinava o "processo de desenvolvimento" reproduzido em consistentes etapas de transformações sociais dos sistemas político, social e econômico das nações em prol de um mercado de consumo de massa.

Com a finalidade de promover o desenvolvimento, a indústria nacional também foi o foco de grandes investimentos e de protecionismo, conforme assinala Fonseca (2003, p. 142), que recorda um discurso realizado em 1931, pelo então Presidente, Getúlio Vargas: "O protecionismo industrial das matérias-primas do país é fator decisivo, sem dúvida, ao nosso progresso econômico. É justo, por isso, que se estimule, mediante política tarifária, conduzida sem excessos. As tabelas das alfândegas devem refletir estes critérios". Cabe destacar que o processo de industrialização voltada para a substituição de importações foi impulsionado pela desvalorização da moeda nacional, uma vez que, a partir da perda do poder de compra de produtos importados, restou constatada a capacidade ociosa de alguns setores da economia. Nesse ponto, Fausto (2006, p. 45) assevera:

Esse fator foi ainda mais importante porque, de olho no equilíbrio da balança comercial, o governo proibiu a importação de máquinas para inúmeras indústrias, excetuando apenas a substituição de bens imprestáveis, entre 1931 e 1937. Em média, no período 1933-39, a indústria cresceu a uma taxa anual de $11,2 \%$, concentrando-se em metalurgia de pequeno porte e bens de consumo, como papel e papelão, têxteis, vestuário e calçados.

Outra medida governamental que impulsionou a indústria foi a ampliação do crédito por parte do Banco do Brasil, na segunda metade dos anos 1930. À época foram criados vários instrumentos: a carteira de redesconto e a carteira de crédito agrícola e industrial. Nesse cenário, o BB assumiu as funções típicas de um banco central até 1945, com a criação da SUMOC (FAUSTO, 2006, p. 5556). A Petrobrás (criada em 1953) e Companhia Siderúrgica Nacional (em 1951) são exemplos de iniciativas que visavam uma maior industrialização do país, por meio da criação de empresas nacionais.

No que se refere à retomada do crescimento, destaca-se que, ao passo que a dívida externa diminuiu (em milhões de dólares) de US\$ 1.240,7 em 1928 para US\$ 
940,6 em 1932, ela alcançou seu menor valor em 1950, voltando a crescer de US\$559, nesse ano, para US\$1.395, em 1955. As exportações e as importações, por seu turno, decaíram até o ano de 1932, quando retomaram o crescimento.

\section{Política econômica e relações comerciais en- tre Brasil e Estados Unidos no primeiro go- verno de Getúlio Vargas}

Em 1930, foi dado início a processo de análise da situação financeira nacional realizada pelo Banco da Inglaterra, que seria conhecido como Missão Niemeyer (GARCIA, 2005, p. 142). A vinda de Otto Niemeyer, que emprestou o nome ao relatório e à missão, insere-se em um contexto de avaliações da estrutura econômica brasileira conduzidas por estrangeiros e brasileiros ao longo das décadas de 1930 e 1940 (BAER, 2009, p. 62). O Relatório Niemeyer considerou os gastos públicos como sendo excessivos e propôs medidas de equilíbrio orçamentário e de estabilização monetária (FAUSTO, 2006, p. 44). Apontou a "diversificação da estrutura econômica brasileira" que era fortemente baseada na agricultura como uma solução ao problema interno (BAER, 2009, p. 33) 3 .

Devido ao abandono do padrão-ouro por parte da Grã-Bretanha, e à forte recessão decorrente da crise de 1929 - em especial a baixa do preço do café, a redução das receitas de exportação e a decorrente queda na entrada de capital estrangeiro -, o país enfrentou dificuldades para honrar seus compromissos externos, tendo que suspender parte do pagamento da dívida externa e renegociar seus acordos. Os esforços culminaram na concessão, por parte do N. M. Rothschild \& Sons Limited, de um empréstimo de consolidação (GARCIA, 2005, p. 142) deno-

\footnotetext{
"Niemeyer, desde o início de 1931, criticou a ideia de que a saída para a crise cambial deveria incluir um terceiro funding loan: alegava que "o homem que afunda três vezes em geral se afoga”, referência aos dois empréstimos anteriores. Sublinhava o tamanho da operação necessária, em contraste com a limitada operação de 1898 , sugeria que a taxa de juros praticável estaria além dos 7\% e insistia que o Brasil necessitava de capital estrangeiro, e que no caso de um funding loan o país estaria se afastando do mercado internacional por um período longo, talvez dez anos. Defendia, como alternativa, um programa de austeridade fiscal e monetária que perseguisse o equilíbrio orçamentário e o fim da emissão monetária, além da constituição de um banco central emissor, para que se viabilizasse a volta do Brasil ao goldexchange standard”. (ABREU, 2002, p. 529)
}

minado historicamente como terceiro fundingloan, que reescalonou a dívida por três anos (FAUSTO, 2006, p. 44).

Em face da situação das contas nacionais, urgia a adoção de novas políticas monetárias e comerciais, tendentes a superar o déficit na balança comercial. Dentre as medidas tomadas em 1931, destacam-se a revisão geral da tarifa aduaneira - que estava vigente desde 1900 (GARCIA, 2005, p. 143) -, e o estabelecimento do monopólio cambial pelo Banco do Brasil, de forma a centralizar as negociações de moeda estrangeira, priorizando as compras do governo e o pagamento da dívida externa quando da distribuição de divisas (FAUSTO, 2006, p. 52). De acordo com Baer (2009, p. 55):

O Brasil foi também o primeiro país da América Latina a introduzir o controle de câmbio e outros controles diretos que, combinados com a desvalorização da moeda, aumentavam o preço das importações, geraram uma queda no valor das importações, possibilitando um aumento do PIB.

Com o intuito de regularizar as relações comerciais, entre 19 de setembro e 31 de dezembro de 1931, foram firmados dezesseis acordos, que continham cláusula de nação mais favorecida, com diversos países europeus e norte-americanos; sendo que, ao final de 1933, essa quantia havia chegado a trinta e um (CERVO; BUENO, 2008, p. 234-239). Todos os mencionados acordos, com exceção daqueles firmados com os Estados Unidos e a Alemanha seriam denunciados pelo país em 1935, devido a fortes pressões do parlamento.

Em 1934, Oswaldo Aranha, o então Ministro da Fazenda de Getúlio Vargas, apresentou um projeto de redução do serviço da dívida externa (GARCIA, 2005, p. 145) que "procurou livrar o país da política negativa dos fundings, pela qual se pagavam juros vencidos com novos títulos da dívida rendendo juros, tentando-se, a partir daí, subordinar o serviço da dívida à situação do balanço de pagamentos" (FAUSTO, 2006, p. 45). À época, o Brasil já havia negociado três fundings: em 1898, 1914 e 1931; entretanto, o problema de seu endividamento externo não havia sido resolvido de forma satisfatória. O "Esquema Aranha”, previu um acordo no qual havia o reconhecimento da incapacidade nacional de arcar de forma integral com os serviços da dívida, ponderando a respeito da diminuição dos juros e amortizações (ABREU, 2002, p. 531) ${ }^{4}$.

\footnotetext{
4 "Depois do golpe de novembro de 1937, o governo brasileiro anunciou a suspensão do serviço de todos os empréstimos externos por três anos. Vargas argumentou que o Brasil havia
} 
Para alcançar os objetivos de seu plano, Vargas ressaltou a necessidade de um crescimento acelerado da economia, que seria alcançado por meio de um misto de investimentos público e privado; sendo este voltado para a produção de bens de consumo e aquele para ser investido em infraestrutura (FONSECA, 2010). Nas palavras de Fonseca (2003, p. 142):

O desenvolvimentismo, assim, foi-se formando e se consolidando como ideologia, ao nortear e justificar o reordenamento de leis e práticas de política econômica, bem como mudanças e criação de instituições. Foram se formando novas crenças, valores, símbolos e padrões de comportamento - ou seja, o amplo significado abarcado pela palavra instituição e que enfatiza sua importância e complexidade, que de forma alguma pode ser reduzido apenas a órgãos, mas abarca todo um conjunto de regras, normas, comportamentos e símbolos.

Diante do contexto econômico internacional pós-crise de 1929, Getúlio Vargas optou por uma estratégia de financiamento do projeto nacional-desenvolvimentista, que abarcava tanto o investimento governamental (a partir de empréstimos obtidos no exterior) quanto o investimento privado (de empresas nacionais e estrangeiras). Trataremos, neste estudo, especificamente de como o país pôde reunir divisas e equalizar a balança comercial, de forma a viabilizar o investimento público nos setores agrícola e de infraestrutura.

Contrair empréstimos nesse momento de contração da oferta de capital no mercado internacional era um desafio a ser enfrentado pelo governo a partir da atuação do Ministério de Relações Exteriores, que adotou uma nova política institucional, cujo objetivo era estabelecer maiores e melhores relações comerciais, tendo renovado "a prática da diplomacia econômica” (CERVO; BUENO, 2008, p. 234). Nesse sentido, a mudança de percepção do interesse nacional aliada ao pragmatismo nas relações exteriores, permitiu ao país um maior poder de barganha no mercado internacional, conforme veremos. Essa

sido forçado a suspender pagamentos por ser impossível, ao mesmo tempo, pagar o serviço e as importações essenciais ao reequipamento do sistema ferroviário e das forças armadas. A alternativa de um novo funding era considerada inaceitável, porque implicava aumento da dívida nominal, já considerada incompatível com a "capacidade de pagamento" do país. Somente em setembro de 1939 foram iniciadas negociações para retomar o pagamento do serviço da dívida, em seguida a compromisso assumido por Aranha, em visita aos Estados Unidos, no início do ano". (ABREU, 2002, p. 531-532). mudança de paradigmas apresentou seus frutos já nos primeiros meses do governo Vargas, quando o país recebeu a missão industrial inglesa de Sheffield e a missão Niemeyer, de origem norte-americana.

Dentre os maiores parceiros comerciais do Brasil no período estavam Grã-Bretanha, Estados Unidos e Alemanha, sendo que o primeiro encontrava-se na condição de maior credor do país e os últimos, como importantes parceiros para a viabilização da política brasileira de "equidistância pragmática" (CERVO; BUENO, 2008, p. 250), fator de barganha internacional para a conclusão de acordos comerciais.

\subsection{Relações Brasil, Estados Unidos e Alemanha no contexto de guerra: a política de barganhas}

Em 1934, foi enviada ao Brasil missão do Federal Reserve Bank of New York, liderada por John Williams. Essa missão tinha como objetivo promover uma análise da política cambial brasileira e apontar soluções aos problemas nacionais. Diante do diagnóstico, em fevereiro de 1935, o Brasil firmou um acordo de livre-comércio com os EUA, com cláusulas de concessões tarifárias recíprocas e de tratamento cambial equitativo (GARCIA, 2005, p. 146); enquanto, em 1936, assinou um acordo com a Alemanha, que previa a prática de comércio compensado.

Com os Estados Unidos, o acordo havia sido subscrito com base na cláusula de nação mais favorecida, de forma a isentar o imposto alfandegário para produtos como o café e o cacau brasileiros (CERVO; BUENO, 2008, p. 254). Por seu turno, o comércio com a Alemanha era realizado por meio de um "sistema em que importações e exportações eram feitas à base de troca de mercadorias, cujos valores eram contabilizados nas "caixas de compensação" de cada país" (CERVO; BUENO, 2008, p. 254-255). Sobre essa questão, Cervo (2001, p. 41-42) relembra que:

Na segunda metade dos anos 30, o Brasil reformulou com senso muito pragmático sua política de comércio exterior, que passou a fundar-se em três princípios: primeiro, aproveitar as rivalidades dos blocos antagônicos em formação para provocar a competição interna e elevar o poder de barganha nas negociações externas; segundo, manter a política de comércio liberal do lado dos Estados Unidos, forçando-os, contudo, a agir em razão das condições de competição provocadas; terceiro, incrementar o intercâmbio com Alemanha (e a Itália) por meio de mecanismos de comércio compensado.

As relações brasileiras com a Alemanha eram vis- 
tas com certa preocupação pelos Estados Unidos, uma vez que a localização geográfica brasileira, além de sua influência no subcontinente eram bastante visadas do ponto de vista estratégico. À medida que as rivalidades se agravavam, várias propostas foram apresentadas ao Brasil com o objetivo de obter uma aliança contra a "ameaça" comunista. Essa divisão geopolítica permitiu a Vargas negociar o apoio brasileiro em troca de "elementos promotores da indústria, como crédito para exportações, investimentos empresariais, fornecimento de máquinas, etc." (CERVO, 2008, p. 44). Almeida afirma que a postura brasileira diante dessa situação de embates ideológicos foi essencial ao desenvolvimento da indústria nacional:

[...] nesse período uma das mais importantes negociações bilaterais da história das relações entre Brasil e Estados Unidos, relativa ao financiamento da implantação da indústria siderúrgica no Brasil, processo iniciado ainda antes da guerra e concluído já durante a fase de aliança estratégica entre os dois países (ALMEIDA, 2006, p. 20).

Somente ao final dos anos 1930, abandonou-se essa política, optando-se pela parceria norte-americana em razão do pan-americanismo e da histórica aproximação entre ambas as nações (BUENO, 2008, p. 234). Ressalta-se que "as relações do Brasil com os Estados Unidos melhoraram ainda mais, não só em razão da presença de Oswaldo Aranha à frente das Relações Exteriores, mas também por causa da crise nas relações com a Alemanha" (CERVO; BUENO, 2008, p. 248).

Em razão do recrudescimento dos conflitos entre os EUA e a Alemanha, e mediante convite do governo norte-americano, no ano de 1939, o Brasil enviou aos Estados Unidos a Missão do chanceler Oswaldo Aranha, com o objetivo de, "por meio da assistência econômica, atrelar o Brasil ao sistema de poder dos Estados Unidos” (CERVO; BUENO, 2008, p. 251). Apesar de não haver obtido os benefícios esperados (CERVO; BUENO, 2008, p. 251), a missão Aranha concluiu “acordos bilaterais de crédito e cooperação econômica, com a liberação de empréstimo norte-americano no valor de US\$ 50 milhões" (GARCIA, 2005, p. 151).

Cabe destacar, nesse contexto de rivalidade, o discurso proferido por Getúlio a bordo do navio Encouraçado Minas Gerais, em 11 de junho de 1941, o qual foi compreendido por muitos como uma alusão de simpatia ao fascismo e crítica ao governo Roosevelt. A reação norte-americana foi negativa e, após movimentos pendulares entre o Eixo e os Aliados, o Brasil decidiu apoiar aos últimos na guerra. Dentre os maiores fatores que influenciaram a decisão brasileira, estava o ataque a Pearl Harbor, as pressões internas e as benesses oferecidas pelos EUA.

A entrada brasileira na guerra foi o fator decisivo que impulsionou o projeto de desenvolvimento nacional, uma vez que a parceria com os Estados Unidos permitiu o reaparelhamento das forças armadas, a criação da Aeronáutica, a construção de uma siderurgia nacional, entre outros projetos. O país recebeu aproximadamente US\$ 360 milhões em equipamento militar durante a guerra, o que representa um total de $73 \%$ do valor que coube aos países latino-americanos no período. Ademais, o Programa de Empréstimo e Arrendamento, de 1941, promoveu o fornecimento ao Brasil de insumos militares (GARCIA, 2005, p. 155). Garcia relembra que somente no ano de 1942, "os Estados Unidos concederam um empréstimo de US\$ 100 milhões para financiar o projeto siderúrgico brasileiro e um crédito de US\$20 milhões para a renovação das forças armadas" (GARCIA, 2005, p. 156). Cabe mencionar que no final do ano de 1943, o país negociou, com o apoio norte-americano, um acordo sobre o pagamento dos serviços das dívidas contraídas até o ano de 1931 com a Grã-Bretanha (GARCIA, 2005, p. 158).

Portanto, pode-se dizer que apesar da baixa poupança doméstica, a poupança externa permitiu o aumento no nível dos investimentos na indústria e na área militar. Essa manutenção de altos índices de investimento somente foi possível com a assinatura de diversos acordos comerciais entre Brasil e EUA, e com o apoio desses nas negociações da dívida externa nacional. O primeiro governo de Vargas obteve êxito na implantação do projeto desenvolvimentista graças a essas relações bilaterais e à conjuntura internacional que permitiu ao país um maior poder de barganha. Entretanto, esse período de bonança começou a declinar com o início do governo de seu sucessor.

Em 1951, princípio do segundo governo getulista, chegou a ser instalada a Comissão Mista Brasil - Estados Unidos para o Desenvolvimento Econômico (JBUSEDC), cujo objetivo era a elaboração de um diagnóstico da economia nacional, com vistas à apresentação de projetos que viabilizassem o desenvolvimento, que obteriam financiamento do BIRD e do EXIMBANK (FONSECA, 2010). Um dos resultados 
positivos dos trabalhos dessa Comissão foi a criação do Banco Nacional de Desenvolvimento Econômico (BNDE), em 20 de junho de 1952 (GARCIA, 2005, p. 171), que financiaria o desenvolvimento da indústria e agricultura nacionais. Apesar de suas contribuições, a Comissão foi desativada em 1953, uma vez que poucos projetos foram desenvolvidos, devido às rígidas regras para concessão de financiamentos.

Duas medidas ortodoxas que geraram uma grande agitação política foram a entrada em vigor da Instrução $\mathrm{n}^{\circ} 70$, da Superintendência da Moeda e do Crédito (SUMOC) - em 09 de outubro de 1953 - e da Lei de Remessa de Lucros, em 05 de janeiro de 1954. A primeira promoveu o encarecimento dos produtos importados, como forma de estimular a produção nacional, ao passo que a segunda, impôs novas "restrições ao capital estrangeiro, limitando a $10 \%$ ao ano a remessa de lucros de dividendos ao exterior "(GARCIA, 2005, p. 172-173). Ambas foram bastante impopulares aos olhos dos parceiros comerciais e dos investidores internacionais, gerando uma grande desconfiança em relação ao país. No segundo governo de Getúlio, as relações Brasil - Estados Unidos já não se encontravam tão firmes quanto no período anterior, ingressando em um novo afastamento.

\section{Considerações finais}

As relações entre Brasil e Estados Unidos foram fundamentais ao desenvolvimento da indústria de base nacional, a uma retomada do preço internacional do café, ao reaparelhamento das forças armadas e para renegociação de dívidas, bem como para a concessão de empréstimos ao país. Durante o primeiro governo de Getúlio Vargas ambos os países se beneficiaram do comércio bilateral, em especial o Brasil, na medida em que fez uso da política de "equidistância pragmática" para obter vantagens tanto da nação norte-americana quanto da alemã.

Dentre as principais fontes que permitiram a viabilização das políticas desenvolvimentistas de Vargas estão o capital dos EUA e da Grã-Bretanha e, em boa medida, o comércio compensado com a Alemanha. Esse último, benéfico não só do ponto de vista da balança de pagamentos, mas das empresas nacionais. Os acordos de LendéLease firmados com os Estados Unidos, bem como a formação de oficiais militares brasileiros junto aos quartéis daquele país viabilizaram a modernização das forças armadas pátrias.

\section{Referências}

ABREU, Marcelo Paiva. Os fundingloans brasileiros: 1838 - 1931. Pesquisa e planejamento econômico, v. 32, n. 3, dez. 2002. Disponível em: <http://ppe.ipea.gov.br/ index.php/ppe/article/viewFile/142/77>. Acesso em: 10 ago. 2010.

ALMEIDA, Paulo Roberto de. As relações do Brasil com os Estados Unidos em perspectiva histórica. In: ALMEIDA, Paulo Roberto de; BARBOSA, Antônio Rubens. Relações Brasil-Estados Unidos: assimetrias e convergências. São Paulo: Saraiva, 2006.

AMSDEN, A. H. A ascensão do "resto": os desafios ao ocidente de economias com industrialização tardia. Trad. Roger Maioli dos Santos. São Paulo: UNESP, 2007.

BAER, Werner. A economia brasileira: uma abordagem profunda da economia brasileira até 2008. São Paulo: Nobel, 2009 .

BAER, Werner. O processo de industrialização no Brasil: sucessos e problemas. (Palestra proferida no Curso de Altos Estudos)

BRESSER-PEREIRA, L. C. Construindo o Estado republicano: democracia e reforma da gestão pública. Rio de Janeiro: FGV, 2009.

CERVO, Amado Luiz. Inserção internacional: formação dos conceitos brasileiros. São Paulo: Saraiva, 2008.

CERVO, Amado Luiz. Relações internacionais da América Latina: velhos e novos paradigmas. Brasília: IBRI, 2001.

CERVO, Amado Luiz; BUENO, Clodoaldo. História da política externa do Brasil. 3. ed. Brasília: Universidade de Brasília, 2008.

CHARLES, C. M.; MUELLER, C. C. Evolução e características do setor público agrícola no Brasil: as bases do seu modesto desempenho. Revista de Economia e Sociologia Rural, v. 26, n. 3, p. 241-274, 1988.

CIMOLI, M.; DOSI, G.; STIGLITZ, J. Industrial policy and development: the political economy of capabilities accumulation. Oxford: Oxford University Press, 2009.

DINIZ, E. (Org.). Globalização, estado e desenvolvimento: dilemas do Brasil no novo milênio. Rio de Janeiro: FGV, 2007.

EVANS, P. Autonomia e parceria: estados e transformação industrial. Rio de Janeiro: UFRJ, 2004.

FAUSTO, Boris. Getúlio Vargas: o poder e o sorriso. São Paulo: Companhia das Letras, 2006. 
FONSECA, Pedro Cezar Dutra. Vargas: o capitalismo em construção. 2. ed. São Paulo: Brasiliense, 1999.

FONSECA, Pedro Cezar Dutra. Sobre a intencionalidade da política industrializante no Brasil na década de 1930. Revista de economia política, São Paulo, n. 89, p. 133-148, jan./mar 2003. Disponível em: <http://www.rep.org.br/ pdf/89-9.pdf $>$. Acesso em: 17 set. 2011.

FONSECA, Pedro Cezar Dutra. Gênese e precursores do desenvolvimentismo no Brasil. Pesquisa e debate, São Paulo, v. 15, n. 2, p. 225-56, jul./dez. 2004.

FONSECA, Pedro Cezar Dutra. Nem ortodoxia nem populismo: o segundo governo Vargas e a economia brasileira. Tempo, Niterói, v. 14, n. 28, p. 19-58, jan./jun. 2010.

FONSECA, Pedro Cezar Dutra. Além da antropofagia: as raízes do desenvolvimentismo brasileiro. (Palestra proferida no Curso de Altos Estudos)
FONSECA, Pedro Cezar Dutra; CARRARO, André. O desenvolvimento econômico no primeiro governo de Vargas (1930-1945).2003.

FURTADO, Celso. Formação econômica do Brasil. 2. ed. São Paulo: Companhia das Letras, 2007.

GARCIA, Eugênio Vargas. Cronologia das relações internacionais do Brasil. 2. ed. Rio de Janeiro: Contraponto, 2005.

LEYS, C. The rise and Fall of Development Theory. Oxford: James Currey, 1996.

MARINHO, D. N. C.; LOURENÇO, L. C. Aspectos do desenvolvimento vinculados à sociedade e ao Estado. In: FERNANDES, A. M.; RANINCHESKI, S. Américas compartilhadas. São Paulo: EdiFrancis, 2009. 